\title{
Self-Medication and Inappropriate drug use in Geriatric Population of Karachi, Pakistan
}

\author{
${ }^{1}$ Dr. Atif Mahmood, ${ }^{2}$ Dr. Danish Haroon Kushtiwala, ${ }^{3}$ Dr. Asima Faisal \\ ${ }^{1}$ Bhitai Dental and Medical College, Mirpur Khas, Sindh \\ ${ }^{2}$ Pzier Pakistan Ltd. \\ ${ }^{3}$ Institute of Business Management
}

\begin{abstract}
:
Objective:To determine the prevalence of geriatric population who usesself-medication. To evaluate the most common illnesses for which self-medication is being used and to know what are the common drugs which are by the geriatric population for self-medication.

Methodology:It was a descriptive cross-sectional study which was conducted in Karachi on geriatric population over the age of 60 years. The study was done in May and August 2014.A total of 124 participants were selected for the study by non-probability purposive sampling. Data was analyzed using SPSS 17. Written informed consent was obtained from each and every participant. Confidentiality and anonymity of the data was ensured.

Results:Results show that $55.6 \%$ of the respondents were between the age of 61 to 65 years old, males respondents were predominant in the study group, all kinds of work status people were included in the study, $84.68 \%$ respondents indicated that they use self-medication in our study population, $70.5 \%$ of them used selfmedication on their own rather than on someone else's advice.Most of the population preferred to use selfmedication because of two reason, 32.4\% because of their previous experience and $28.6 \%$ used self-medication as per their convenience. The most common symptoms to use self-medication are headache (46.0\%) and pain elsewhere (37.1\%). Pain killers are the most commonly used self-medication(64.5\%) followed by herbal medications.

Conclusion:In our study the prevalence of self-medication was high as compared to other studies conducted in Pakistan, in this study it was found that most common symptoms for which self-medication was used are headache and pain elsewhere, and pain killers are the most common drugs which are being used by the old age people.
\end{abstract}

Keywords:Self-medication, Geriatric population, Head ache, Analgesics

\section{Introduction:}

Self-medication is an area of healthcare in which the patient assumes a greater degree of responsibility for the management of a minor ailment, using a pharmaceutical product that is available without the prescription and using it without the professional advice.(1)The tendency of using over the counter (OTC) medicine is common in many cultures and it is usually common practice in developing countries and WHO regarded selfmedication as a part of self-care. $(2,3)$

In countries where drugs are not strictly regulated,self-medication is more common because of the easy access to all drugs. Over the counter availability of drugs facilitates self-medication and increases the access of people to different kind of medications.(3-5)

Drugs when used irrationally without the prescription of the physicians may cause additional problem instead of curing the present illness.(4, 6)On the brighter side,self-medication when used responsibly and carefully is a resource saving phenomena in the health system.(6)

Self-medication is being practiced all over the world with different frequency in different age groups.(6-8)Reported prevalence is up to $68 \%$ in European countries, while higher in developing countries that are upto $92 \%$ in adolescents in Kuwait.(9) Few studies have been conducted in Pakistan which shows the prevalence reported as 51\%. In Pakistan none of the drugs have OTC status from the Pakistan Drug regulatory authority but in reality all medication are available without prescription at all pharmacies and almost every pharmacy sells drugs without prescription; a phenomenon seen in many developing countries. $(10,11)$

In appropriate drug use refers to the use of medications that should be entirely avoided, or should never be taken in excessive dosage, and should not be used for longer periods of time other than the time period mentioned by the physician or the drug manufacturing company. Inappropriate medication is more common in older adults compared to young people.(12-14)Elderly patients appear to be particularly vulnerable to the adverse consequences of drug non-compliance, because they generally take more drugs, often have multiple chronic illnesses and, therefore, often have complex medication regimens.(15) 
Two studies have been conducted in Pakistan on self-medication, both in university students, both studies were done to find out the prevalence of self-medication among university students, according to these there was high prevalence of self-medication in medical students although they were aware of the harmful effects.(16) Second study was again conducted in university students which claimed the same result that prevalence was high in educated youth despite of knowing the side effects of the drugs.(10) In this study they find out the most common reasons of self-medication was past experience and common symptoms for selfmedication were headache $74.2 \%$, flu $65.5 \%$ and fever $55.2 \%$ while most common medications used were analgesics $88.3 \%$, antipyretics $65.1 \%$ and antibiotics $35.2 \%$.

In Pakistan, the risk of self-medication and inappropriate drug age is higher as compared to other countries because all the medicines are available over the counter without prescription and the people who are dealing the patients at the pharmacy counter are mostly not pharmacist and they give advice to the patients on their own experience, they are not trained to suggest any medication and they do not have the appropriate knowledge to do so. They learn from their own experience and the results of different drugs which they hear from the patient coming to them again for consultation.

To the best of our knowledge, previously there has been not a single study that has been published related to self-medication among geriatric population in Pakistan. This objective of the study was to find out the prevalence of self-medication among geriatric population. The study also aimed to evaluate the most common complains for which self-medication is used and themost common drugs used in self-medication by the geriatric population.

\section{Material and methods:}

It was descriptive cross sectional study conducted on the Geriatric population (Elderly people), ages from 60 years and above of Karachi from May 2014 to August 2014.

Karachi is divided into 5 districts (South, East, Malir, WestandCentral). Samples were collected from each district by Non probability purposive sampling.

The Sample Size was calculated using the formula $\left(Z^{2} * p^{*}[1-p]\right) / c^{2}$ and was found to be 121 for $0.05 \mathrm{CI}$ Where $Z=Z$ value (e.g. 1.96 for $95 \%$ confidence level), $\mathrm{p}=$ percentage picking a choice, expressed as decimal(.086 used for sample size needed because $4.3 \%$ population of Pakistan is between 55 to 64 years of age and $4.3 \%$ population is 65 years and over - total of $8.6 \%$ population 55 years and above)Source: Central Intelligence Agency (CIA), 2014, c = confidence interval, expressed as decimal(e.g., .05 $= \pm 5$ )

A self-administered survey questionnaire wasused. The contents of questionnaire were developed based on previously published literature, validated and pre-tested for reliability in selected area which is similar to the actual area of interest of our study too.

A total of 124 Questionnaires were circulated. Data collected was entered and analyzed using Statistical Package for Social Sciences Program (SPSS) version 17. The frequencies and percentages for variables were calculated. Written informed consent was obtained from each and every participant and confidentiality and anonymity was ensured.

\section{Results}

Result shows that $55.6 \%$ of the respondents were between the ages of 61 to 65 years, male respondents were predominant in the study group (69.4\%). Our study population mostly consists of graduates $(34.7 \%)$ and undergraduates (22.6\%), 4 (3.2\%) hadno major qualification but Diplomas or certificate courses. Most of the subjects $(82.3 \%)$ of the study population weremarried.All participants had been associated with some kind of work in their past; majority were still working in private sector $(30.6 \%)$ while 27.4 were associated with some business. Twenty eight $(22.6 \%)$ were spending a retired life. In our study population, majority of the subjects(almost 54\%)were earning more than 25,000 per month. (Table 1)

The practice of self-medication was found in $84.68 \%$ respondents.Majority $(70.5 \%)$ said that they have used self-medication on their own, 32.4\% said referred to use self-medication on the basis of their previous experience. $28.6 \%$ said they had used self-medication as per their own convenience. (Figure 1 and 2)

The most common reason to use self-medication was found to headache $(46.0 \%)$ followed by pain elsewhere (37.1).Pain killers were the most commonly used self-medication $(64.5 \%)$ followed by herbal and homeopathic medication which were the second most commonly used self-medication (27.4\%). (Figure 3 and 4 ) 
Table 1: Demographics of the respondents

\begin{tabular}{|c|c|c|c|}
\hline Demographics & & Frequency $(\mathrm{N}=124)$ & $\begin{array}{l}\text { Percentage } \\
(\%)\end{array}$ \\
\hline \multirow[t]{3}{*}{ Age Groups } & 61-65 years & 41 & 55.6 \\
\hline & 65-70 years & 69 & 29.0 \\
\hline & $>70$ years & 31 & 15.3 \\
\hline \multirow[t]{2}{*}{ Gender } & Male & 86 & 69.4 \\
\hline & Female & 38 & 30.6 \\
\hline \multirow[t]{4}{*}{ Marital Status } & Single & 4 & 3.2 \\
\hline & Married & 102 & 82.3 \\
\hline & Divorced & 4 & 3.2 \\
\hline & Widowed & 14 & 11.3 \\
\hline \multirow[t]{6}{*}{ Educational Status } & Post-graduate & 16 & 12.9 \\
\hline & Graduate & 43 & 34.7 \\
\hline & Undergraduate & 28 & 22.6 \\
\hline & High school/intermediate & 19 & 15.3 \\
\hline & Matriculation & 14 & 11.3 \\
\hline & Others & 4 & 3.2 \\
\hline \multirow[t]{4}{*}{ Employment Status } & Retired & 28 & 22.6 \\
\hline & Private job & 38 & 30.6 \\
\hline & Self-employed/business & 34 & 27.4 \\
\hline & House wives & 24 & 19.4 \\
\hline \multirow[t]{5}{*}{ Monthly Income } & Less than 10,000 & 4 & 3.2 \\
\hline & $10,001-25,000$ & 28 & 22.6 \\
\hline & $25,001-50,000$ & 24 & 19.4 \\
\hline & more than 50,000 & 43 & 34.7 \\
\hline & Not earning anything & 25 & 20.2 \\
\hline
\end{tabular}

Figure 1: Pie Chart of Do you useself-medication

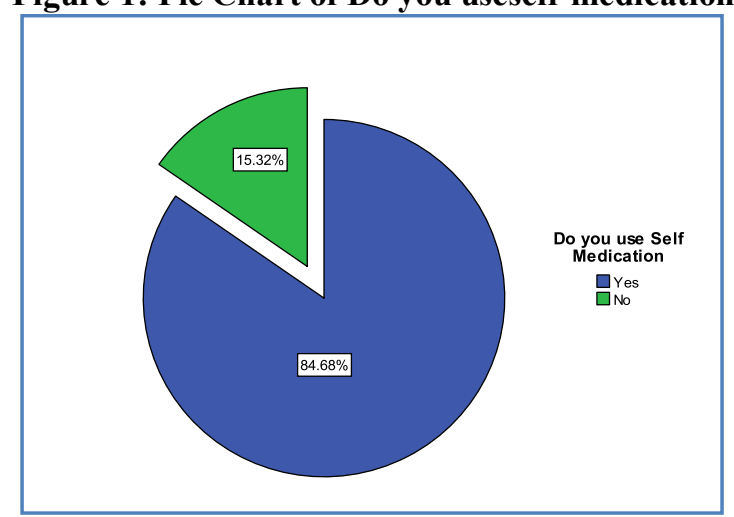

Figure 2: How do you use self-medication?

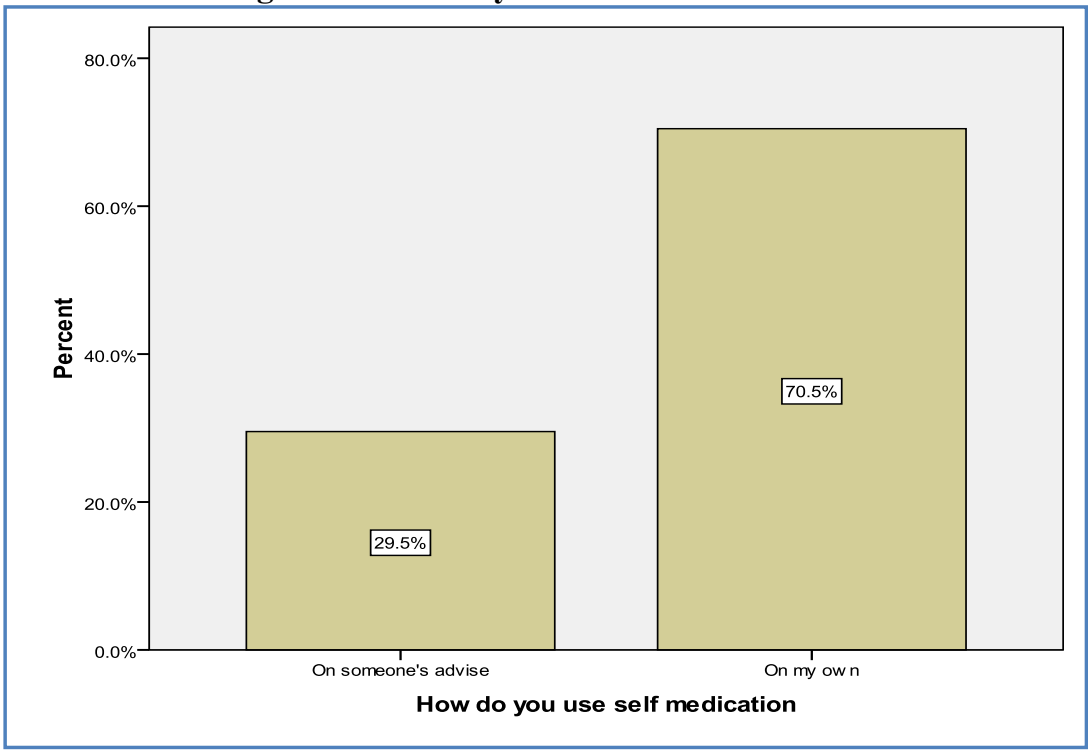


Fig 3: Bar Graph Symptoms for which Self-medication is used

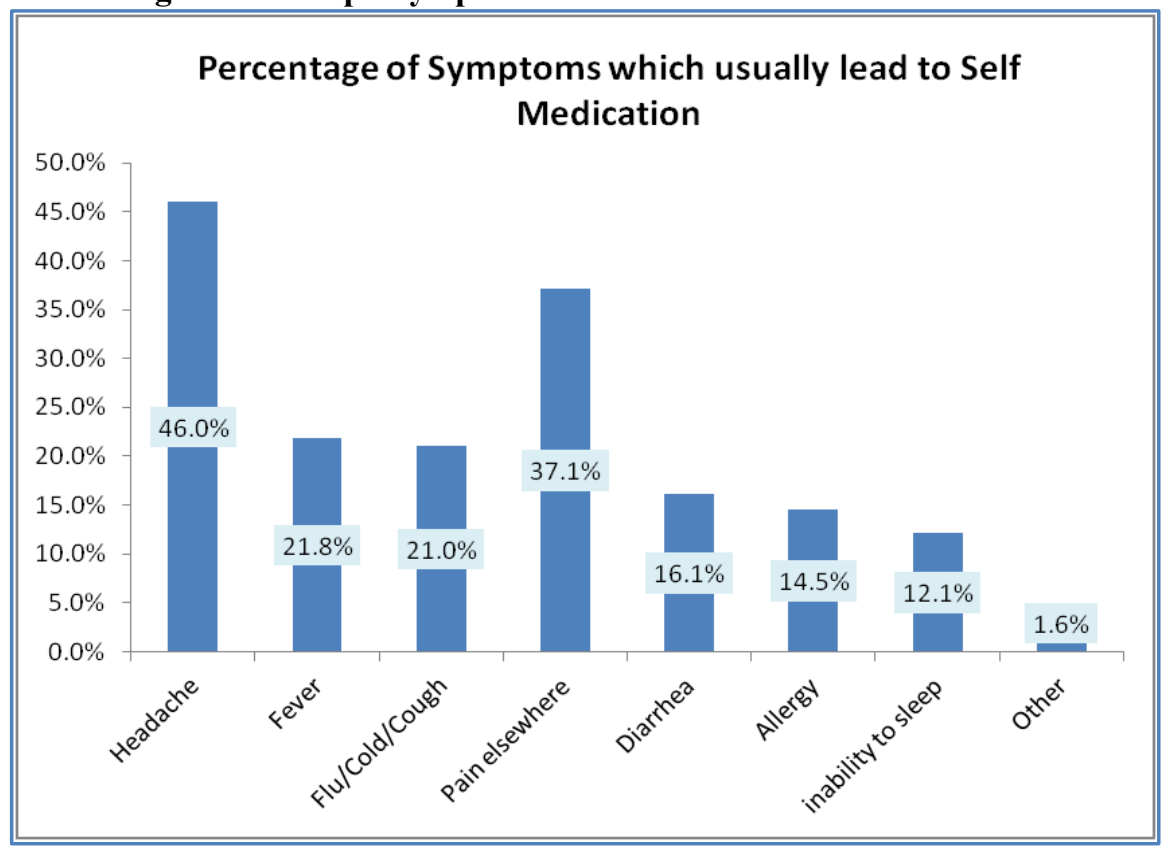

Fig 4: Commonest drugs which are used to self-medication

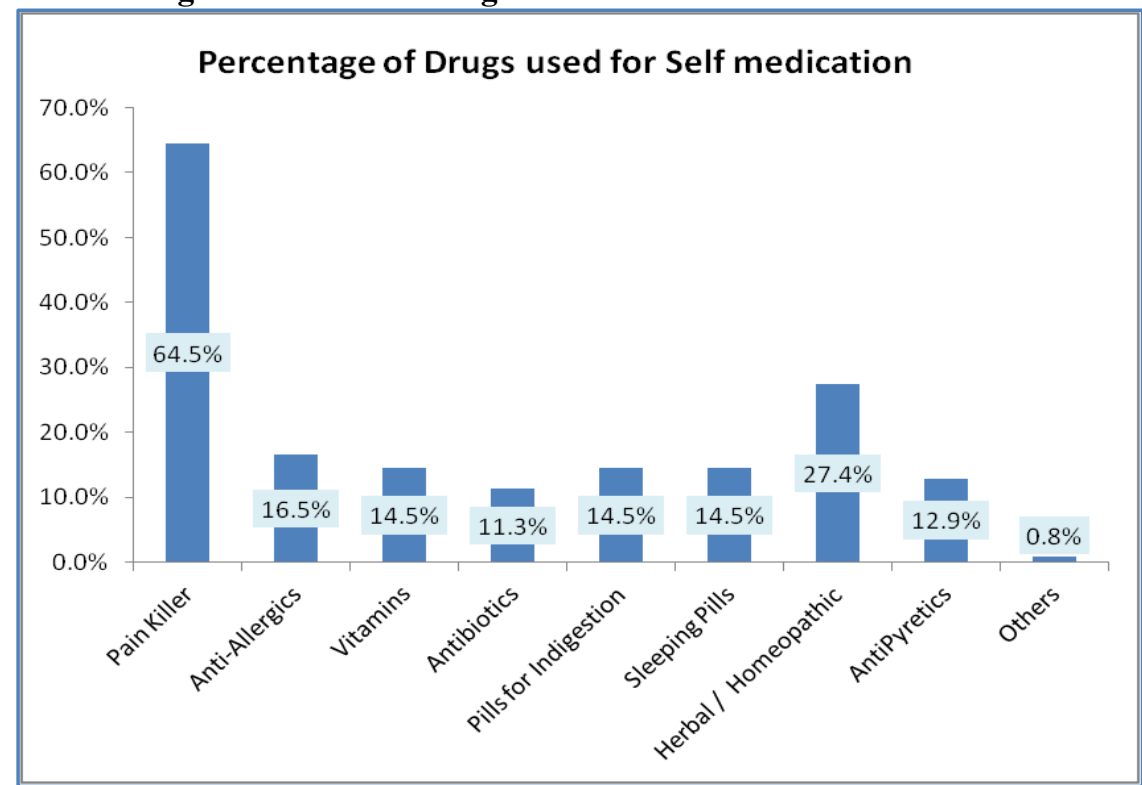

\section{Discussion}

The survey was conducted to find out the practice of self-medication in elderly population of Karachi, Pakistan. More than $84 \%$ of our selected population was found to be using self-medication; this prevalence of self-medication is high as compared to prevalence of about $68 \%$ reported in European countries whereasother developing countries like Kuwait have reported the prevalence of self-medicationto beas high as $92 \%$.In Pakistan, no study was conducted on elderly population but twostudieswere conducted in university students of Karachi and their survey reported $76 \%$ and $80 \%$ prevalence of self-medication respectively. $(10,16)$ The reason for higher prevalence of self-medicationamong elderly might relate toseveralyears of their experience with selfmedication and that they have gone to doctors over the years for different complains and thus, have been prescribed medication for different illnesses.At an elderly age they might perceive themselves as knowledgeable regarding the use of medications for minor illnesses.

In this survey it was found that three forth of the elderly population uses self-medication on their own discretion without any advice and the population which uses self-medication on their own discretion mostly practiceself-medication because of their past experience and at the same time they also look for convenience 
while resolving minor illnesses, while the respondents who indicated that they use self-medication on someone's advice, most of them mentioned that they are using self-medication on some friends and family's advice, in a study done on university students in Karachi, Pakistan also identified that half of the students in their study groups preferred self-medication because of their past experience.(10)

The most common symptoms which lead to self-medication according to two previous studies published in Pakistan in 2008 and 2012 were Headache, Flu and fever(10, 16) while Jain, P. et. al., in India found out the most common symptoms to be GI symptoms and headache/fever.(17) In this survey, the most common symptom for which the respondent started self-medicationwas headache followed by pain elsewherewhich was the second most common symptom, while fever and flu/cold were the $3^{\text {rd }}$ most common symptoms. Headache hasbeen reported as the most common symptom by other studies while the reason for pain elsewhere as the second most common symptom could be explained by the fact that the prevalence of bone diseases are very common in the elderly population of Pakistan.

In our study, the most common drugs which were used as self-medication were pain killers (64\%) and herbal/ homeopathic medications (27\%), most of the other studies also suggested pain killers as the most commonly used drugs for self-medication. Study conducted in Brazil found that analgesics 56\% (pain killers) were the most common drugs used for self-medication followed by anti-histamines (anti-allergic).(3) In another study conducted in South Australia, it was found that analgesics, laxatives and low dose aspirin were the most commonly used drugs.(18)

In present study, more than $90 \%$ of the people who usedself-medication were satisfied with its use and considered it safe based on their past experiences while a study conducted in university students in Karachi indicated that more than half of their study population knew that self-medication could be harmful. (16)

\section{Conclusion}

In our study, the prevalence of self-medication was highas compared to other studies conducted in Pakistan. In this study, headache and pain elsewherewere found to be the most common symptoms for which self-medication was used, and pain killers were the most common drugs which were being used by the old age people.

\section{Recommendation}

Use of self-medication is increasing all over the world but in a developing country like Pakistan where literacy rate is quite low and all the medications are available over the counter it is the responsibility of the drug regulatory authority (DRA) to minimize the use of self-medication and should not allow pharmacies to give medicines to the people without the prescription of a certified doctor as with increasing self-medication practice there is more risk of side effects and misuse or drug abuse related.

There should be awareness campaigns on self-medication practice for the knowledge of non-medical related population of Pakistan so that they can analyze the risk benefit ratio before taking any medication.

Doctors should be advised to tell the patients about the side effect and overdose of whatever they prescribe to the patient so that they have knowledge if they decide to take the same medication in future without the consultation of Doctor

\section{References}

[1]. Hughes CM, McElnay JC, Fleming GF. Benefits and risks of self medication. Drug Safety. 2001;24(14):1027-37.

[2]. Gul H, Omurtag G, Clark PM, Tozan A, Ozel S. Nonprescription medication purchases and the role of pharmacists as healthcare workers in self-medication in Istanbul. Medical Science Monitor. 2007;13(7):PH9-PH14.

[3]. Bertoldi AD, Camargo AL, Silveira MPT, Menezes A, Assuncao MCF, Goncalves H, et al. Self-medication among adolescents aged 18 years: the 1993 Pelotas (Brazil) Birth Cohort Study. Journal of Adolescent Health. 2014;55(2):175-81.

[4]. Auta A, Banwat SB, Sariem CN, Shalkur D, Nasara B, Atuluku MO. Medicines in Pharmacy Students' Residence Selfmedication Practices. Journal of Young Pharmacists. 2012;4(2):119-23.

[5]. Osemene KP, Lamikanra A. A study of the prevalence of self-medication practice among university students in Southwestern Nigeria. Tropical Journal of Pharmaceutical Research. 2012;11(4):683-9.

[6]. Eickhoff C, HÃămmerlein A, Griese N, Schulz M. Nature and frequency of drugâ€国elated problems in selfâ€? ?medication (overâ€国theâ€止counter drugs) in daily community pharmacy practice in Germany. Pharmacoepidemiology and drug safety. 2012;21(3):254-60.

[7]. Charuptanapong N. Perceived likelihood of risks in self medication practices. Journal of Social and Administrative Pharmacy. 1994;11:18-.

[8]. Farker K, Rottenkolber M, Drewelow B. Patient self-medication and serious adverse drug reactions (ADRs). Br J Clin Pharmacol. 2009;68((Suppl. 1)):56-8.

[9]. Abahussain EA, Matowe LK, Nicholls PJ. Self-reported medication use among adolescents in Kuwait. Medical principles and practice. 2005;14(3):161-4.

[10]. Zafar SN, Syed R, Waqar S, Zubairi AJ, Vaqar T, Shaikh M, et al. Self-medication amongst university students of Karachi: prevalence, knowledge and attitudes. Journal of the Pakistan Medical Association. 2008;58(4):214.

[11]. Hussain A, Khanum A. Self medication among university students of Islamabad, Pakistan-a preliminary study. Southern Med Review. 2008;1(1):14-6. 
[12]. Zuckerman IH, Langenberg P, Baumgarten M, Orwig D, Byrns PJ, Simoni-Wastila L, et al. Inappropriate drug use and risk of transition to nursing homes among community-dwelling older adults. Medical care. 2006;44(8):722.

[13]. Stuck AE, Beers MH, Steiner A, Aronow HU, Rubenstein LZ, Beck JC. Inappropriate medication use in community-residing older persons. Archives of Internal Medicine. 1994;154(19):2195-200.

[14]. Laroche ML, Charmes JP, Nouaille Y, Picard N, Merle L. Is inappropriate medication use a major cause of adverse drug reactions in the elderly? British journal of clinical pharmacology. 2007;63(2):177-86.

[15]. McElnay JC, McCallion CR, Al-Deagi F, Scott M. Self-reported medication non-compliance in the elderly. European journal of clinical pharmacology. 1997;53(3-4):171-8.

[16]. Mumtaz Y, Jahangeer SMA, Mujtaba T, Zafar S, Adnan S. Self medication among university students of Karachi. JLUMHS. $2011 ; 10(03): 102-5$

[17]. Jain P, Sachan A, Singla RK, Agrawal P. Statistical Study on Self Medication Pattern in Haryana, India. Indo Global Journal of Pharmaceutical Sciences. 2012;2(1):21-35.

[18]. Goh LY, Vitry AI, Semple SJ, Esterman A, Luszcz MA. Self-medication with over-the-counter drugs and complementary medications in South Australia's elderly population. BMC complementary and alternative medicine. 2009;9(1):42. 